\title{
Effect of Systemic Isotretinoin Treatment on Melasma: A Case Study and Literature Review
}

\section{Lenz $\mathrm{CR}^{1 *}$ and Aldrich $\mathrm{SL}^{2}$ \\ ${ }^{1}$ Peterson Air Force Base, USA \\ ${ }^{2}$ Dermatologist, United States Air Force Academy, USA}

*Corresponding author: Crystal R Lenz, Flight surgeon at Peterson Air Force Base in Colorado, 9653 Rockingham Dr Peyton, CO 80831, USA, Tel: 719-493-4685; Email: D0Lenz25@gmail.com

\section{Case Report \\ Volume 4 Issue 2}

Received Date: June 12, 2019

Published Date: July 04, 2019

DOI: $10.23880 /$ cdoaj-16000182

\section{Abstract}

Melasma is a commonly acquired hyper-melanotic condition characterized by brown to grey colored irregular macules and patches on sun-exposed surfaces of the skin, most commonly on the malar prominence and forehead. It is most common in females, generally of childbearing age, and especially prominent in darker skinned individuals, particularly those of Asian descent. Chronic ultraviolet (UV) light exposure, genetic factors and reproductive hormones are generally accepted to be contributing factors to this process, however the exact pathogenesis has not been fully elucidated.

The current gold standard in melasma treatment is lightening cream containing hydroquinone (HQ). Tretinoin can be added to increase efficacy, and the combination of both agents plus a topical corticosteroid is the most effective regimen currently available. Overuse can lead to fixed erythema and telangiectasias, acneiform eruptions and hypertrichosis. Other treatment options with minimal to moderate efficacy include methimazole, azelaic acid, kojic acid, vitamin $\mathrm{C}$, and arbutin.

Some studies indicate that mequinol (4-hydroxyanisole; 4-HA) 2\% may actually be a more effective depigmentation agent than hydroquinone $3 \%$, and it's use in combination with tretinoin $0.01 \%$ has shown efficacy in treating solar lentigines, with decreased incidence of skin irritation in swine models, but there is currently insufficient evidence to support this finding in human subjects.

Various procedures such as peels and laser or light-based treatments have been proposed as effective treatments, but with mixed results in published clinical studies. These treatments also carry a risk of skin irritation and either hyper- or hypopigmentation or even scarring. We present a case of melasma that demonstrated marked improvement after a course of systemic isotretinoin targeting acne.

Keywords: Melasma; Isotretinoin treatment 
Abbreviations: HQ: Hydroquinone; UV: Chronic ultraviolet; ECM: Extracellular Matrix; MMPs: Metalloproteinases; VEGF: Vascular Endothelial Growth Factor; FGF-2: Fibroblast Growth Factor-2; TGF- $\beta$ : Transforming Growth Factor Beta; TCC: Triple Combination Cream; PIH: Post-Inflammatory Hyperpigmentation; TA: Tranexamic Acid; bFGF: Basic Fibroblast Growth Factor.

\section{Case Report}

A 43-year-old Caucasian woman presented to a new dermatology clinic for evaluation and treatment of acne affecting her back and chest. It had been present for approximately five years, and was typically worse to the back and chest during menstruation. Though previous medical records were unavailable for review, the patient reported trying many different topical and oral medications in the past, with some response to oral contraceptives. She stopped the contraceptives, however, because she developed melasma that was cosmetically troubling to her. She tried spironolactone but did not find it helpful for her acne. She reported no significant improvement with oral antibiotics or prescription acne washes. Upon establishing care in this new office, she did an additional trial in Nov 2016 of systemic doxycycline combined with a $5 \%$ benzoyl peroxide wash and $0.1 \%$ tretinoin cream. Acne was unchanged after five months of treatment so topical $1 \%$ clindamycin phosphate lotion was added and tretinoin was changed to tazorac $1 \%$ gel. After 3 months with these therapies, her acne was again unchanged. After discussion of all treatment options, the decision was made to proceed with systemic isotretinoin treatment.

For melasma, the patient reported prior treatment with triple combination therapy (fluocinolone acetonide $0.01 \%$ / hydroquinone $4 \%$ / tretinoin $0.05 \%$ ) without significant fading. She also tried several over the counter fading creams and at home chemical peels without significant or lasting improvement. At the time of presentation she was not currently treating her melasma but desired treatment due to the bothersome appearance. She was started on hydroquinone $4 \%$ twice daily plus tretinoin $0.1 \%$ cream once daily (for acne as well). Sun protection with a physical blocker was also recommended. After 5 months of treatment her melasma was slightly faded but still bothersome to her. At that time, tretinoin was changed to tazorac $0.1 \%$ gel to improve her acne and for simplicity this was also applied to her melasama. After 3 months on hydroquinone $4 \%$ and tazorac $0.1 \%$ her melasma was unchanged. At this time she was started on oral isotretinoin for her acne. When on isotretinoin, hydroquinone was continued. All other topical acne medications were discontinued. She completed a full course of oral isotretinoin, $150 \mathrm{mg} / \mathrm{kg}$ dosed at $1 \mathrm{mg} / \mathrm{kg}$, with clearance of acne and a drastic improvement in her melasma as well. Figures 1 through 6 show the clinical response of this patient's melasma to systemic isotretinoin treatment.

Five months after completion of isotretinoin treatment, her acne has not recurred, nor has her melasma. She continues to use topical tretinoin $0.1 \%$ cream daily as well as $4 \%$ hydroquinone twice daily and is very pleased with her results.
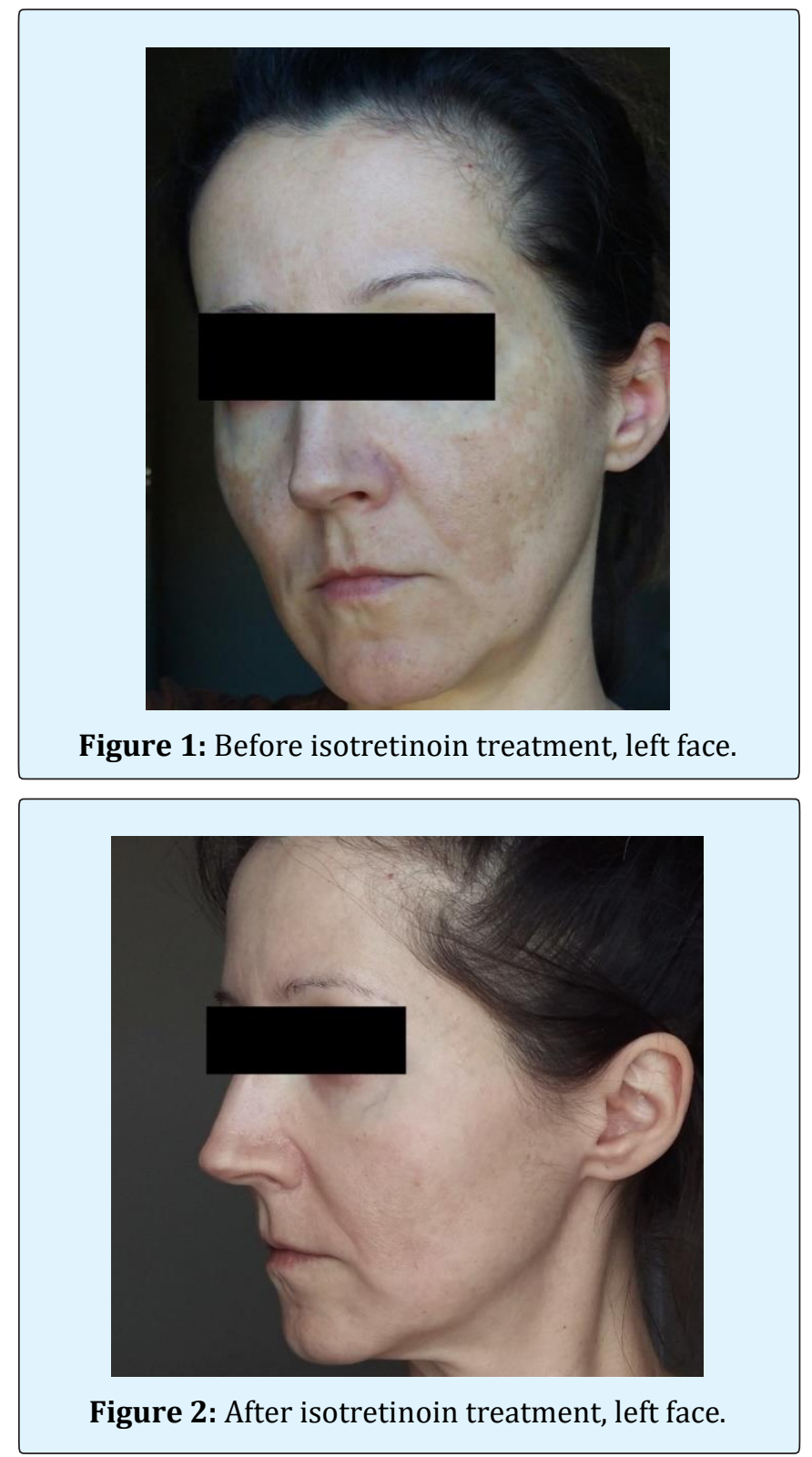


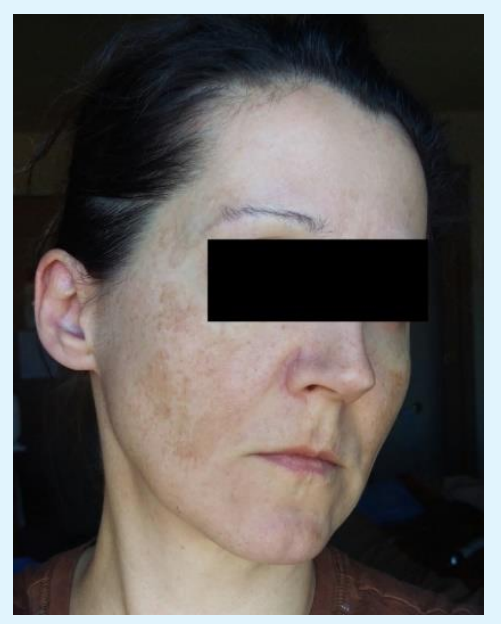

Figure 3: Before isotretinoin treatment, right face.

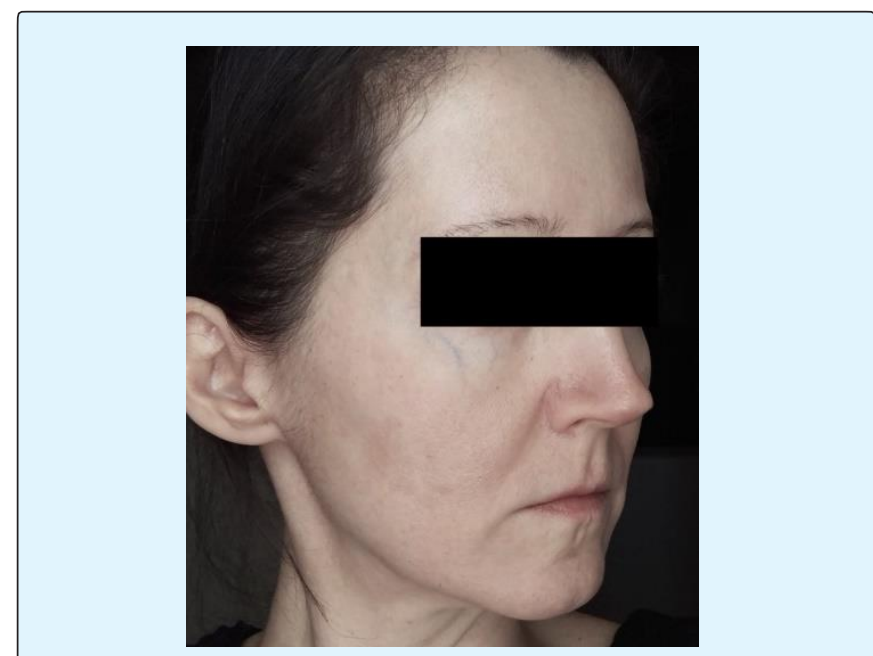

Figure 4: After isotretinoin treatment, right face.

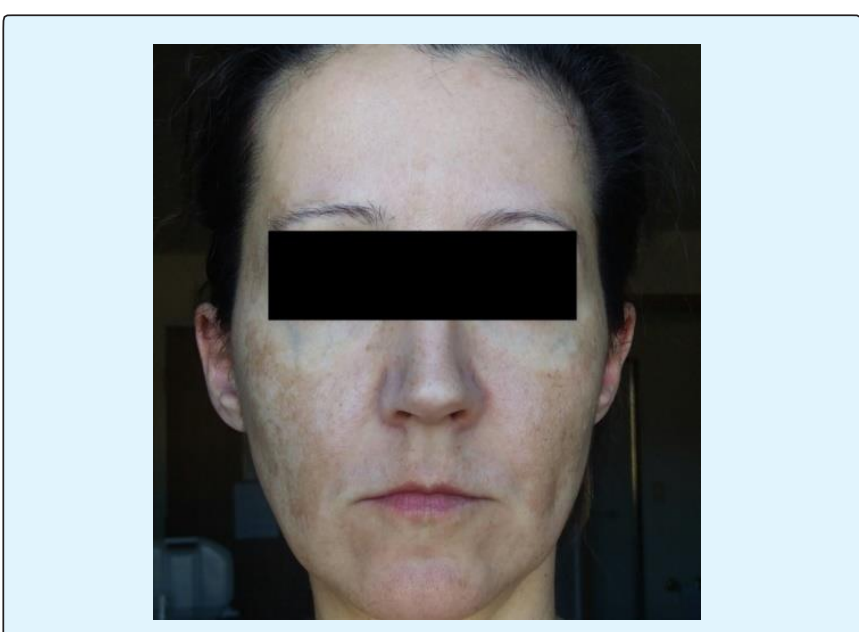

Figure 5: Before isotretinoin treatment, frontal face.

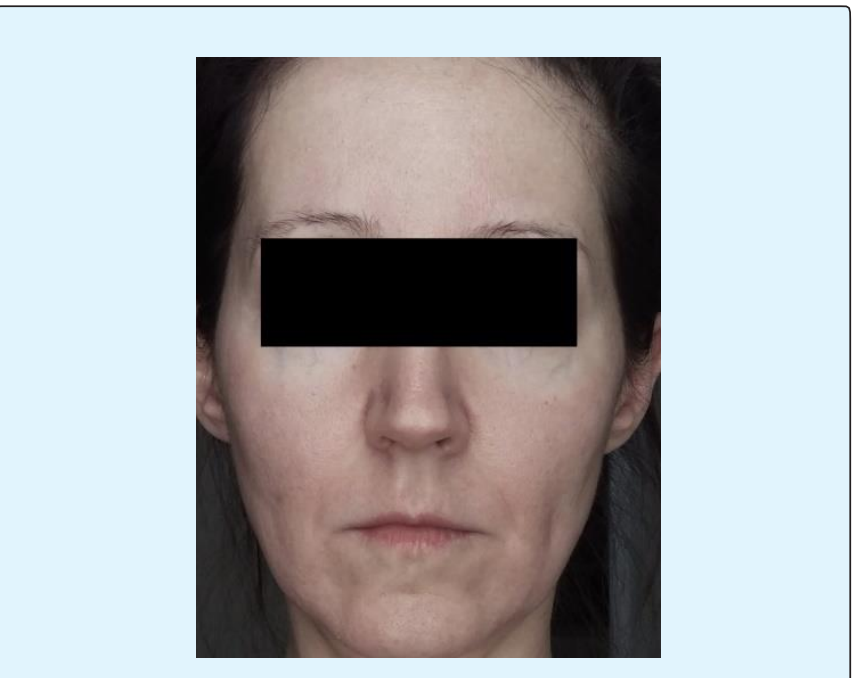

Figure 6: After isotretinoin treatment, frontal face.

\section{Discussion}

Melasma is a common and often cosmetically distressing condition disproportionately affecting women of childbearing age. It is often recurrent and or refractory to treatment, and current treatment options are limited.

Investigations into the pathophysiology of melasma have demonstrated several key components that are targeted through current treatment modalities. Dermal Extracellular Matrix (ECM) abnormality, specifically solar elastosis, has been demonstrated with $83 \%$ presence in lesional skin compared to $29 \%$ in perilesional skin [1-3]. Histologically, the elastic fibers appeared thicker, highly curled, and more fragmented than those in unaffected skin [4]. This greater degree of solar elastosis indicates a crucial role of photo-aging in the development of melisma [5]. Basement membrane disruption through degradation of type IV collagen is another key feature, allowing for descent of melanocytes and melanin into the dermis and rendering melasma refractory to treatment and more likely to recur. Increased vascularization is an additional characteristic of skin affected by melasma, with studies showing a $68.75 \%$ increase in vascularization of melasma skin as compared to unaffected skin [6]. Finally, there is evidence of increased number of mast cells present in melasma skin, with one study utilizing immunohistochemical staining to show an average of 58 mast cells per square millimeter of melasma skin, compared to 37 in unaffected skin [3]. Histamine release from dermal mast cells has been shown to be upregulated by ultraviolet irradiation, and histamine does play a role in melanogenesis as well $[7,8]$. Mast cells seem to play a particularly key role in the pathogenesis of 


\section{Clinical Dermatology Open Access Journal}

melasma as they contribute by four separate pathways. Histamine directly stimulates proliferation and migration of melanocytes [9]. Mast cell tryptases activate pro-matrix metalloproteinases (MMPs) which, as active MMPs, damage ECM proteins leading to solar elastosis and degrade type IV collagen, weakening the basement membrane [10,11]. Finally, mast cells induce vascular proliferation via secretion of angiogenic factors including vascular endothelial growth factor (VEGF), fibroblast growth factor-2 (FGF-2) and transforming growth factor beta (TGF- $\beta$ ) [12].

The above considerations are important when approaching treatment strategies for melasma. Hydroquinone (HQ), the gold standard melasma treatment at present, works via blocking conversion of 13,4-dihydroxyphenylalanine to melanin via competitive inhibition of tyrosinase which is the rate limiting enzyme in melanogenesis. A triple combination cream (TCC) with $4 \% \quad \mathrm{HQ} \quad 0.05 \%$ tretinoin and $0.01 \%$ fluocinolone acetonide is the most effective topical treatment available at present [13]. Steroids reduce inflammation as well as inhibit secretion of endothelin-1 and granulocyte macrophage colony-stimulating factor which are involved in UV-induced melanogenesis $[14,15]$. Concern over longterm corticosteroid use and the telangiectasia and skin atrophy that can result from this treatment has prompted further investigation into non-steroidal treatment options. Some studies have demonstrated similar efficacy of microencapsulated hydroquinone $4 \%$ and retinol $0.15 \%$ (retinol is converted to tretinoin in the skin) [16].

Topical retinoids have a well-established role in the treatment of melasma as well as other pigmentary disorders such as actinic lentigines and postinflammatory hyperpigmentation (PIH). They are most often used in triple combination therapy with hydroquinone and a corticosteroid as previously noted, though monotherapy with first generation non-aromatic retinoid (tretinoin) has also shown potential benefit. The underlying mechanism is thought to be related to accelerated epidermal turnover [16]. Tretinoin also inhibits UVB-induced tyrosinase and tyrosine-related protein 1 expression which inhibit melanin synthesis [17], and there is further evidence that retinoids decrease melanosome transfer [18]. A literature review of all published studies on the efficacy of retinoids in hyperpigmentation disorders found grade $B$ evidence that 40 weeks of topical tretinoin $0.1 \%$ may be effective to treat melasma and found insufficient evidence to support the use of topical isotretinoin $0.05 \%$ gel or adapalene $0.1 \%$ alone for this condition [16].
While the mainstay of melasma treatment is topical, there is interest in and some evidence to support systemic therapies, particularly in severe and refractory cases. The most well studied and validated systemic treatment at present is tranexamic acid (TA), which inhibits plasmin, preventing conversion of extracellular matrix bound VEGF into its free forms [19]. It also suppresses neovascularization-induced basic fibroblast growth factor (bFGF) [20], and studies have shown a significant decrease in the lesional melanin index and erythema index after oral doses of $250 \mathrm{mg}$ three times daily for eight weeks [21]. Tranexamic acid has also been used as a topical and intra-lesional microinjection for skin lightening purposes [22]. As topical retinoids already have an established role in the treatment of melasma, perhaps systemic retinoids could follow a similar path and become a viable systemic treatment option for melasma and other pigmentary disorders.

As retinoids have been most widely used in the treatment of acne, we see in related literature that topical retinoids work through normalization of keratinization within the follicle and anti-inflammatory actions. Similarly, systemic isotretinoin supports keratinocyte differentiation, helps normalize desquamation and reduces inflammation through suppression of proinflammatory cytokines [23].

Isotretinoin (13-cis-retinoic acid) is metabolized in the body to at least five biologically important metabolites, one of which is tretinoin (all-trans-retinoic acid). It is the well-established most efficacious treatment currently available for acne. The most common and concerning documented side effects include over-drying and irritation of the skin and teratogenicity, respectively. These effects are dose dependent and can be mitigated by ensuring dual contraception in women and liberal use of moisturizers and lip balms during treatment [24].

\section{Conclusion}

Melasma is a common hyper-pigmentary condition that is often persistent or relapsing and with limited satisfactory treatment options at present. While the mainstay of melasma treatment is currently topical therapy, there is increasing interest in systemic therapy options. This case demonstrates a possible role for systemic isotretinoin in the treatment of refractory cases of melasma, perhaps working synergistically with topical hydroquinone. Nonsteroidal treatments may show benefit over current gold standard triple creams by avoiding the common side effects of telangiectasia and skin atrophy seen with prolonged use. Further studies are needed to investigate 
efficacy of systemic isotretinoin in melasma, and determine if effects may be long lasting as they are in the treatment of acne.

\section{References}

1. James WD, Berger TG, Elston DM, Neuhaus IM (2016) Andrews' Diseases of the Skin: Clinical Dermatology, Twelfth Edition. Philadelphia, PA: Elsevier, pp: 858.

2. Nair X, Parab P, Suhr L, Tramposch KM (1993) Combination of 4-hydroxyanisole and all-trans retinoic acid produces synergistic skin depigmentation in swine. J Invest Dermatol 101(2): 145-149.

3. Torres-Alvarez B, Mesa-Garza IG, Castanedo-Cazares JP, Fuentes-Ahumada C, Oros-Ovalle C, et al. (2011) Histochemical and immunohistochemical study in melasma: Evidence of damage in the basal membrane. Am J Dermatopathol 33(3): 291-295.

4. Kang WH, Yoon KH, Lee ES, Kim J, Lee KB, et al. (2002) Melasma: Histopathological Characteristics in 56 Korean Patients. Br J Dermatol 146: 228-237.

5. Soon-Hyo K, Young-Ji H, Soo-Keun L, Kyoung-Chan P (2016) Heterogeneous Pathology of Melasma and Its Clinical Implications. Int J Mol Sci 17(6): 824.

6. Kim EH, Park HY, Yaar M, Gilchrest BA (2005) Modulation of Vascular Endothelial Growth Factor Receptors in Melanocytes. Exp Dermatol 14(8): 625633.

7. Malaviya R, Morrison AR, Pentaland AP (1996) Histamine in Human Epidermal Cells is Induced by Ultraviolet Light Injury. J Investig Dermatol 106(4): 785-789.

8. Gilchrest BA, Soter NA, Stoff JS, Mihm MC Jr (1981) The Human Sunburn Reaction: Histologic and Biochemical Studies. J Am Acad Dermatol 5(4): 411422.

9. Kim NH, Lee AY (2010) Histamine Effect on Melanocyte Proliferation and Vitiliginous Keratinocyte Survival. Exp Dermatol 19(12): 10731079.

10. Bosset S, Bonnet-Duquennoy M, Barre P, Chalon A, Kurfurst R, et al. (2003) Photoaging Shows Histological Features of Chronic Skin Inflammation
Without Clinical and Molecular Abnormalities. Br J Dermatol 149(4): 826-835.

11. Iddamalgoda A, Le QT, Ito $K$, Tanaka $K$, Kojima $H$, et al. (2008) Mast Cell Tryptase and Photoaging: Possible Involvement in the Degradation of Extra Cellular Matrix and Basement Membrane Proteins. Arch Dermatol Res 300(1): 569-576.

12. Crivellato E, Nico B, Ribatti D (2008) Mast Cells and Tumour Angiogenesis: New Insight From Experimental Carcinogenesis. Cancer Lett 269(1): 1-6.

13. Ball Arefiev KL, Hantash BM (2012) Advances in the Treatment of Melasma: A Review of the Recent Literature. Dermatol Surg 38(7): 971-984.

14. Lee IW, Lee SC, Kim DS, Kim HJ, Park KC (2001) Effects of Dexamethasone on Endothein-1 (ET-1) Production by Keratinocytes. Ann Dermatol 13(3): 148-152.

15. Kim DS, Kim HJ, Choi KH, Chung JH, Kim KH, Park KC (2001) UVB-induced GM-CSF Production is Suppressed by Dexamethasone in HaCaT Cells. Photodermatol Photoimmunol Photomed 17(3): 121125.

16. Hee YK, Valerio V, Bahadoran P, Ortonne JP (2009) The Role of Topical Retinoids in the Treatment of Pigmentary Disorders. Am J Clin Dermatol 10(4): 251260.

17. Romero C, Aberdam E, Larnier C, Ortonne JP (1994) Retinoic acid as modulator of UVB-induced melanocyte differentiation: involvement of the melanogenic enzymes expression. J Cell Sci 107(4): 1095-1103.

18. Ortonne JP (2006) Retinoid therapy of pigmented disorders. Dermatol Ther 19(5): 280-288.

19. Ferrara N (2010) Binding to the Extracellular Matrix and Proteolytic Processing: Two Key Mechanisms Regulating Vascular Endothelial Growth Factor Action. Mol Biol Cell 21(5): 687-690.

20. Bastaki M, Nelli EE, Dell'Era P, Rusnati M, MolinariTosatti MP, et al. (1997) Basic Fibroblast Growth Factor-Induced Angiogenic Phenotype in Mouse Endothelium: A Study of Aortic and Microvascular Endothelial Cell Lines. Arterioscler Thromb Vasc Biol 17(3): 454-464. 
21. Na JI, Choi SY, Yang SH, Choi HR, Kang HY, et al. (2013) Effect of Tranexamic Acid on Melasma: A Clinical Trial with Histological Evaluation. J Eur Acad Dermatol Venereol 27(8): 1035-1039.

22. Shin JU, Park J, Oh SH, Lee JH (2013) Oral Tranexamic Acid Enhances the Efficacy of Low-fluence 1064-Nm quality-switched neodymium-doped yttrium aluminum garnet laser treatment for melasma in
Koreans: a randomized, prospective trial. Dermatol Surg 39(3): 435-442.

23. Baldwin HE, Leyden JJ, Webster GF, Zaenglein AL (2015) Challenges in the Treatment of Acne in the United States. Dermatology News 2015: 7-8.

24. Layton A (2009) Review: The use of isotretinoin in acne. Dermato-Endocrinology 1(3): 162-169. 